\title{
Evaluation of the separation performance of polyvinylpyrrolidone as a virtual stationary phase for chromatographic NMR
}

\author{
Shaohua Huang, ${ }^{a *}$ Rui Wu, ${ }^{b}$ Zhengwu Bai, ${ }^{b * *}$ Ying Yang, ${ }^{a}$ Suying $\mathrm{Li}^{\mathrm{a}}$ \\ and Xiaowei Dou ${ }^{a}$
}

Polyvinylpyrrolidone (PVP) was used as a virtual stationary phase to separate $p$-xylene, benzyl alcohol, and p-methylphenol by the chromatographic NMR technique. The effects of concentration and weight-average molecular weight (Mw) of PVP, solvent viscosity, solvent polarity, and sample temperature on the resolution of these components were investigated. It was found that both higher PVP concentration and higher PVP Mw caused the increase of diffusion resolution for the three components. Moreover, the diffusion resolution did not change at viscosity-higher solvents. Moreover, the three components showed different resolution at different solvents. As temperature increased, the diffusion resolution between $p$-xylene and benzyl alcohol gradually increased, and the one between $p$-xylene and $p$-methylphenol slightly increased from 278 to $298 \mathrm{~K}$ and then decreased above $298 \mathrm{~K}$. It was also found that the polarity of the analytes played an important role for the separation by affecting the diffusion coefficient. Copyright $\odot 2014$ John Wiley \& Sons, Ltd.

Keywords: NMR; ${ }^{1} \mathrm{H}$; chromatographic NMR; polyvinylpyrrolidone; virtual stationary phase; diffusion resolution

\section{Introduction}

Diffusion-ordered spectroscopy (DOSY) in NMR is a new effective tool for the analyses of complicated mixture. ${ }^{[1-4]}$ In DOSY experiment, the diffusion coefficients $(D)$ related to separated components are plotted on the vertical axis (F1), while the chemical shifts in the spectrum yielded by each component are plotted on the horizontal axis (F2). ${ }^{[5]}$ Herein, $D$ is described by the Stokes-Einstein equation:

$$
D=\frac{k T}{6 \pi \eta r_{s}}
$$

where, $k$ is the Boltzmann constant, $T$ refers to the temperature, $\eta$ represents the viscosity of the liquid, and $r_{s}$ is the (hydrodynamic) radius of the molecule. From the Stokes-Einstein equation, it is obvious that $T, \eta$, and $r_{s}$ are the three important factors.

The application of DOSY has been dubbed chromatographic NMR (CNMR) ${ }^{[4,6-8]}$ which can be evaluated by the diffusion resolution with a formula:

$$
\Delta D=D_{A 1}-D_{A 2}
$$

where, $D_{\mathrm{A} 1}$ is the $D$ of analyte 1 (A1) and $D_{\mathrm{A} 2}$ is the $D$ of analyte 2 (A2), respectively. $D$ depends on many physical parameters such as mass, size, and shape of a molecule, sample temperature, and viscosity of analyses system. Therefore, a complicated mixture can be fully separated as long as the differences in some physical parameters of each component are prominent enough. However, it is not easy to obtain a desirable resolution only through the pulsed field gradient NMR technique, especially for these components which bear similar molecular properties. A practical approach to solve this problem is adding some polymer, ${ }^{[9-11]}$ surfactant, ${ }^{[12-14]}$ microemulsion, ${ }^{[15-19]}$, or silica gel ${ }^{[3,20-26]}$ in NMR tube or NMR rotor as a matrix or a virtual stationary phase (VSP) to enlarge the difference of diffusion rates of the components. DOSY techniques can discriminate complex components very well by using these additives. Up to now, there is no report concerning the influences of experimental conditions on the resolution. In order to further understand the mechanism of CNMR and to enlarge the application scope of this technique, it is of significance to observe the influence of these conditions such as VSP type, solvent viscosity, solvent polarity, and sample temperature on the separation. In 2009, Kavakka J. S. et al. ${ }^{[9]}$ reported that PVP (refer to Fig. 1) can fully separate a mixture of $p$-xylene, benzyl alcohol, and $p$-methylphenol by ${ }^{1} \mathrm{H}$ CNMR technique, but the effect of 'chromatographic conditions' on diffusion resolution was not studied. In this work, we employed PVP as a VSP and evaluated its separation performance in ${ }^{1} \mathrm{H}$ CNMR under different conditions including concentration and Mw of PVP, solvent viscosity, solvent polarity, and sample temperature.

* Correspondence to: Shaohua Huang, Key Laboratory of Biobased Materials, Qingdao Institute of Bioenergy and Bioprocess Technology, Chinese Academy of Sciences, Qingdao 266101, China. E-mail: huangsh@qibebt.ac.cn

** Correspondence to: Zhengwu Bai, School of Chemistry and Environmental Engineering, Wuhan Institute of Technology, Wuhan 430073, China. E-mail: zhengwu_bai@yahoo.com

a Key Laboratory of Biobased Materials, Qingdao Institute of Bioenergy and Bioprocess Technology, Chinese Academy of Sciences, Qingdao 266101, China

b School of Chemistry and Environmental Engineering, Wuhan Institute of Technology, Wuhan 430073, China 


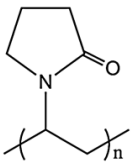

Figure 1. Structure of PVP.

\section{Experimental}

\section{Chemicals and instruments}

PVPs with different Mws (Mw $=10000,24000,58000 \mathrm{~g} / \mathrm{mol}$ ) were purchased from Chengdu Ai Keda Chemical Technology Co., Ltd. (China) and used without pre-treatment. p-Xylene, benzyl alcohol, $p$-methylphenol, and $\mathrm{CCl}_{4}$ were all obtained from Sinopharm Chemical Reagent Co., Ltd. (China) and used as received. $\mathrm{CDCl}_{3}$ and $\mathrm{CD}_{3} \mathrm{OD}$ were purchased from Cambridge Isotope Laboratories, Inc. (USA) with $0.003 \%(\mathrm{v} / \mathrm{v})$ TMS as internal standard. CNMR measurements were conducted on a high-resolution liquid NMR $600 \mathrm{MHz}$ spectrometer of Bruker Avance III (Sweden) with a $5 \mathrm{~mm} \mathrm{TCl}$ CryoProbe equipped with Z-gradients up to $53 \mathrm{~g} / \mathrm{cm}$ operating at $600.13 \mathrm{MHz}$.

\section{NMR experiments}

In all CNMR experiments, the DOSY data sets were measured using four steady-state scans, eight transients, and $1.5 \mathrm{~s}$ relaxation delay. Spectral width in ${ }^{1} \mathrm{H}$-dimension was $7211.539 \mathrm{~Hz}$, and the number of acquired complex data points was 4096. Diffusion was measured using a LEDBPGPCPMG2S pulse sequence, ramping the strongest gradient from 2 to $95 \%$ of maximum strength in 30 steps. Spoil gradient duration was $0.6 \mathrm{~ms}$, and eddy current recovery delay was $5 \mathrm{~ms}$. Diffusion gradient duration and diffusion time were given according to the practical needs. The duration of Carr-PurcellMeiboom-Gill (CPMG)-filter of $1 \mathrm{~ms}$ was used, and the total length of CPMG-train for polymer signal suppression was $60 \mathrm{~ms}$. Sample temperature was set at $298 \mathrm{~K}$ except when indicated. The data was apodized by sine function and zerofilled up to 16384 complex points prior to Fourier transformation. The 2D DOSY data set was processed by using the command DOSY2D in Bruker TopSpin 3.1 spectrometer operating software. Notably, bipolar longitudinal eddy current delay with gradients (LEDBPGP ${ }^{[27]}$ ) pulse sequence was modified in order to make this sequence include a T2-filter element (CPMG spin echo train, $\mathrm{CPMG}^{[28,29]}$ ) prior to the acquisition period. This modified pulse sequence was named as LEDBPGPCPMG2S shown in Fig. 2.

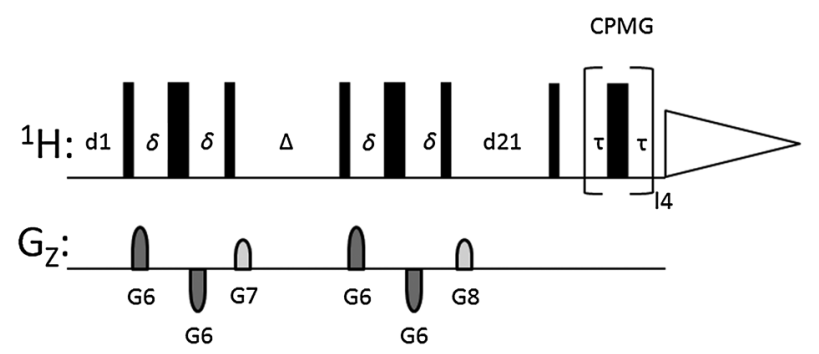

Figure 2. Pulse sequence for LEDBPGPCPMG2S.

\section{Results and Discussion}

In CNMR experiments, the additive structure should be preferably simple, avoiding the possible overlap with analyte signals. In addition, VSP must not cause too high viscosity for the solvent, otherwise resulting in line broadening of analyte signals. Based on this consideration and the reported observations, ${ }^{[9]}$ PVP was selected as the VSP and a mixture of $p$-xylene, benzyl alcohol, and $p$-methylphenol as the analyte in this work. $\mathrm{CDCl}_{3}$ was used as the NMR solvent to form a 'normal-phase' system because the molecular polarity of PVP is higher than that of $\mathrm{CDCl}_{3}$. Besides, pulse program with $T_{2}$ filtering in CNMR measurements was loaded in order to suppress the VSP signals. Under these conditions, the three components in the mixture were not separated in DOSY spectra in the absence of PVP (Fig. 3(a)), and on the contrary, $p$-xylene, benzyl alcohol, and p-methylphenol were satisfactorily resolved in the presence of PVP (Fig. 3(b)). The result of this CNMR measurement demonstrates that PVP is a preferable VSP for these three components.

\section{Influence of PVP concentration on diffusion coefficient and resolution}

Figure 4 shows the influence of PVP concentration $(C)$ on $D$ and $\Delta D$ values. As seen in Fig. 4, $D$ values of three components became small as PVP concentration increased. Moreover, the absolute value of the slope (designed as $S$ ) of the reduction in $D$ values of these three components is in a sequence of $S_{p \text {-xylene }}$ $S_{\text {benzyl alcohol }}<S_{p \text {-methylphenol }}$. This sequence correlates the component polarity, which is in a sequence of $p$-xylene $<$ benzyl alcohol $<p$-methylphenol. As shown in Fig. $4, \Delta D_{1}\left(D_{p \text {-xylene }}-D_{\text {benzyl }}\right.$ alcohol $)$ and $\Delta D_{2}\left(D_{p \text {-xylene }}-D_{p \text {-methylphenol }}\right)$ were enlarged as PVP concentration increased. The slopes of the increase in $\Delta D_{1}$ and $\Delta D_{2}$ values were higher when $C$ was lower than $25 \mathrm{mg} / \mathrm{ml}$, revealing that the components were resolved better at the higher concentrations of PVP. However, PVP limitedly improved the resolutions when $C$ was higher than $25 \mathrm{mg} / \mathrm{ml}$.

In fact, when PVP was fed at an increasing amount, more structural units of $N$-vinylpyrrolidone in the solvent interacted with the components causing the increases of $\Delta D$. On the other hand, more PVP brought about a higher viscosity of the solvent, and as a result, the diffusion of the components was restricted. This trend was evidenced by the decrease of $D$. The increase of $\Delta D$ was accordingly limited when PVP was fed at a concentration above $25 \mathrm{mg} / \mathrm{ml}$.

\section{Influence of PVP Mw on diffusion coefficient and resolution}

Another important factor impacting $D$ and $\Delta D$ is the Mw of VSP. In the present work, three PVPs of different Mws were exploited as VSPs. The dependence of $D$ and $\Delta D$ on the Mws is presented in Fig. 5. As shown in Fig. 5, $D$ values of three components reduced as the Mw of PVPs increased and decreased very slowly when the $\mathrm{Mw}$ was more than $24000 \mathrm{~g} / \mathrm{mol}$. Two $\Delta D$ values were enlarged as the increase of Mw and were almost invariable when Mw was between 24000 and $58000 \mathrm{~g} / \mathrm{mol}$. The weight of PVPs of different $\mathrm{Mw}$ was fed by $50 \mathrm{mg}$ in $0.6 \mathrm{ml} \mathrm{CDCl}_{3}$. In each experiment, the number of structural units was same for each VSP. Therefore, the changes in $D$ and $\Delta D$ values were created by the different Mw of the polymers. The chain of PVPs of higher Mw twins hinders the motion of the components and further reduces $\Delta D$. This observation demonstrates that a certain amount of $\mathrm{Mw}$ 

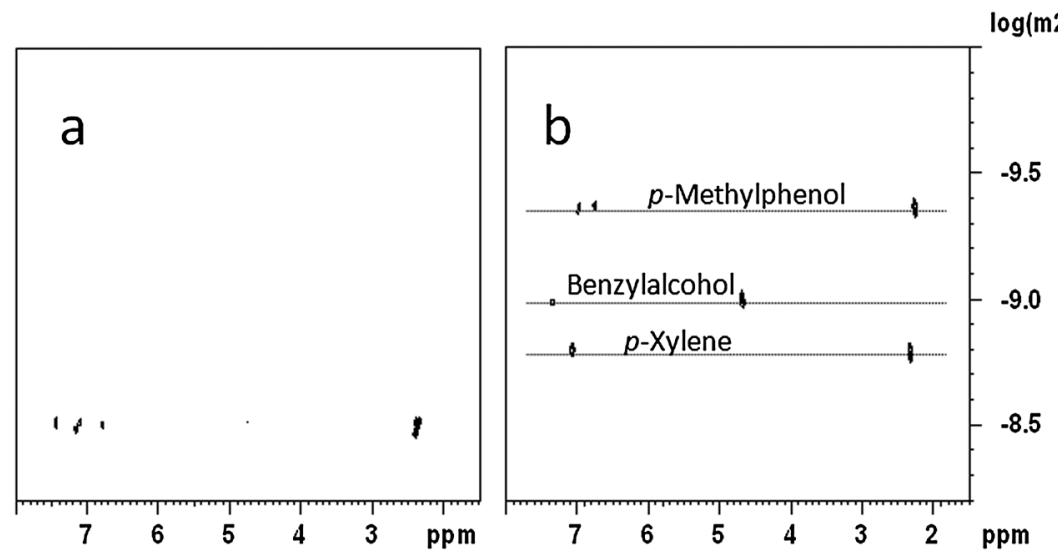

Figure 3. ${ }^{1} \mathrm{H}$ CNMR spectra $(600 \mathrm{MHz})$ of mixture including $p$-xylene $(20 \mathrm{mg})$, benzyl alcohol $(20 \mathrm{mg})$, and $p$-methylphenol (20 mg) before (a) and after (b) adding $50 \mathrm{mg}$ PVP $(\mathrm{Mw}=10000 \mathrm{~g} / \mathrm{mol})$ in $0.6 \mathrm{ml} \mathrm{CDCl} 3$ when $T$ was set at $298 \mathrm{~K}$.

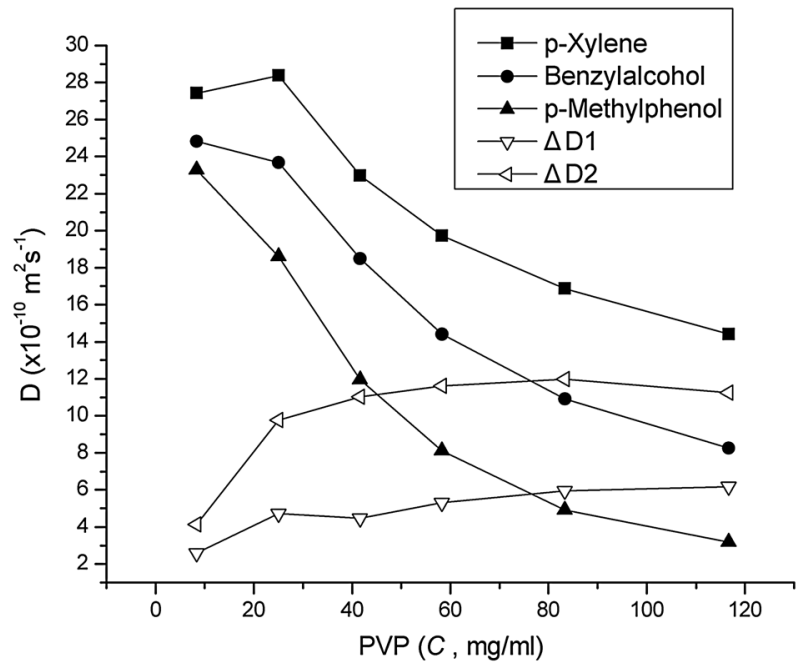

Figure 4. Influence of PVP concentration $(C)$ on diffusion coefficient and resolution. PVP Mw: $10000 \mathrm{~g} / \mathrm{mol}$; each component: $20 \mathrm{mg}$; solvent: $0.6 \mathrm{ml}$ $\mathrm{CDCl}_{3} ;$ T: $298 \mathrm{~K}$.

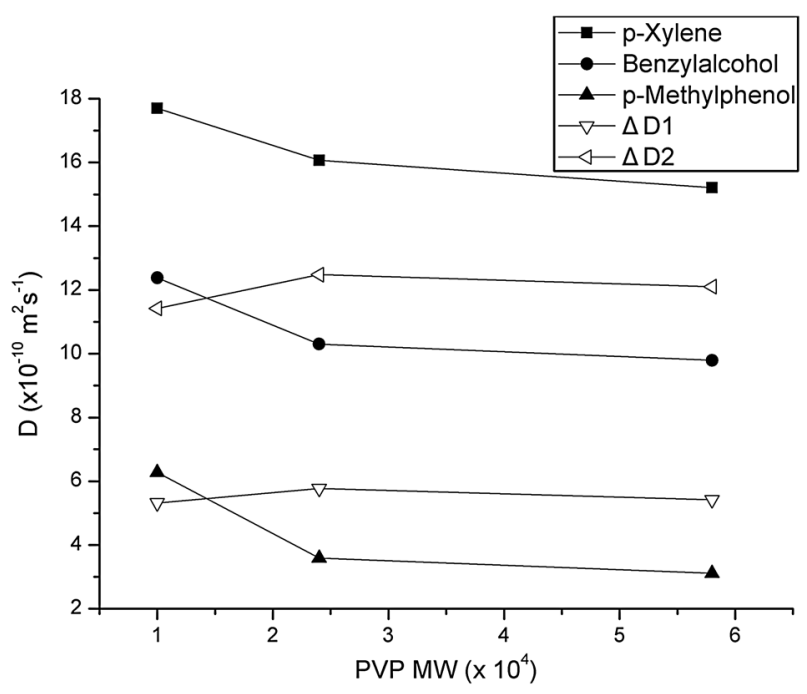

Figure 5. Influence of PVP Mw on diffusion coefficient and resolution. PVP: 50 mg; each component: $20 \mathrm{mg}$; solvent: $0.6 \mathrm{ml} \mathrm{CDCl}{ }_{3} ;$ T: $298 \mathrm{~K}$. is necessary for a VSP to separate components of a sample. However, higher Mw may not be favorable for better resolution.

\section{Influence of solvent viscosity and polarity on diffusion coef- ficient and resolution}

Solvent is an important element impacting experiment results in chromatography, especially in liquid chromatography and thin layer chromatography. ${ }^{[30-33]}$ Solvent properties such as viscosity and polarity etc., influence the existing state of a sample molecule in solvent and further affect the retention properties such as retention factor, selectivity, and resolution. Similarly, the solvents in CNMR may also affect separation performance of a VSP.

When the measurement was conducted, $\mathrm{CDCl}_{3}$ was employed as the solvent and $\mathrm{CCl}_{4}$ as a viscosity modifier. The viscosity of $\mathrm{CDCl}_{3}$ is $0.54 \mathrm{mPa}$ s and is $0.91 \mathrm{mPa}$ s for $\mathrm{CCl}_{4}$ at $25^{\circ} \mathrm{C}$. The effect of solvent viscosity on $D$ and $\Delta D$ values is presented in Fig. 6 . As shown in Fig. $6, D$ values of three components reduced as the increase of $\mathrm{CCl}_{4}$ in solvent. Obviously, the solvent of higher viscosity impedes the diffusion of components, resulting in the decrease in $D$ values of the components. Additionally, $D$ value may be related to the polarity of the components. $D$ value is in

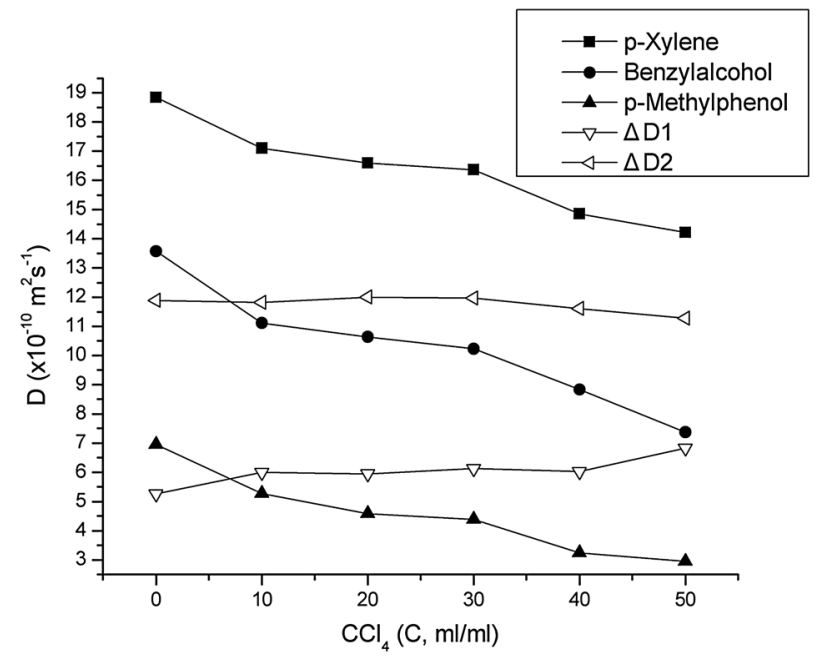

Figure 6. Influence of solvent viscosity on diffusion coefficient and resolution. PVP Mw: $10000 \mathrm{~g} / \mathrm{mol}$; PVP: $50 \mathrm{mg}$; each component: $5 \mathrm{mg}$; solvent volume: $0.6 \mathrm{ml} ;$ T: $298 \mathrm{~K}$. 

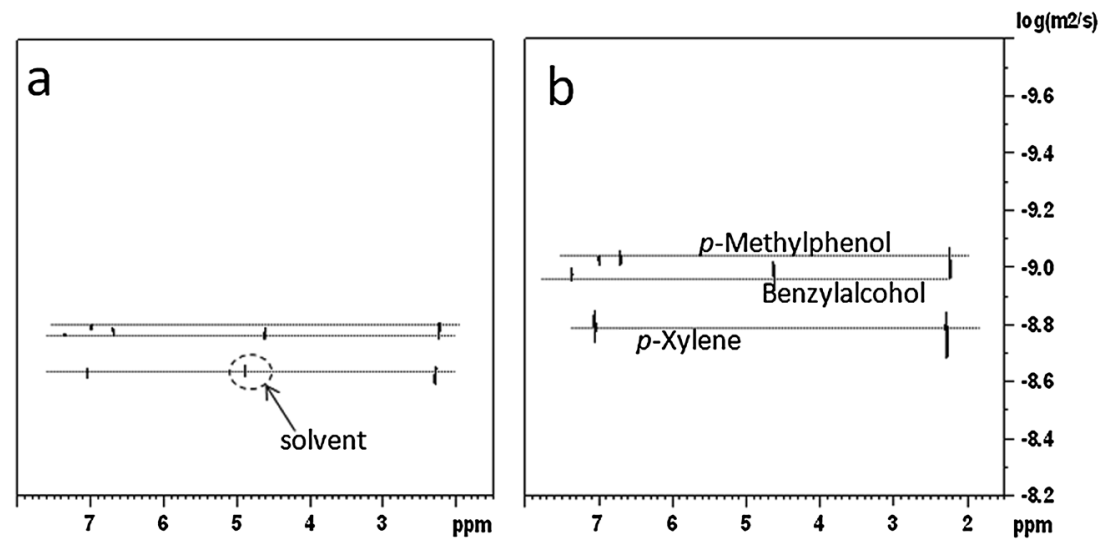

Figure 7. ${ }^{1} \mathrm{H}$ CNMR spectra $(600 \mathrm{MHz})$ of mixture including $p$-xylene $(20 \mathrm{mg})$, benzyl alcohol $(20 \mathrm{mg})$, and $p$-methylphenol $(20 \mathrm{mg})$ before (a) and after (b) adding $50 \mathrm{mg}$ PVP $(\mathrm{Mw}=10000 \mathrm{~g} / \mathrm{mol})$ in $0.6 \mathrm{ml} \mathrm{CD}{ }_{3} \mathrm{OD}$ when $T$ was set at $298 \mathrm{~K}$.

a sequence of $D_{p \text {-xylene }}>D_{\text {benzyl alcohol }}>D_{p \text {-methylphenol, while }}$ the polarity is in a sequence of $p$-xylene $<$ benzyl alcohol $<p$-methylphenol. The two reversed sequences imply that the component of lower polarity shows higher diffusion. In the measurements, the solvent was $\mathrm{CDCl}_{3}$ or a mixture of $\mathrm{CDCl}_{3}$ and $\mathrm{CCl}_{4}$. Chloro group is an electron-rich substituent. The hydroxyls in p-methylphenol and benzyl alcohol interacted with the chloro groups of the solvents, decreasing the diffusion of the two components. Because the acidity of $p$-methylphenol is stronger than that of benzyl alcohol, $p$-methylphenol interacts stronger with chloro group than benzyl alcohol. Therefore, the $D$ value of $p$-methylphenol should be lower than that of benzyl alcohol, and $p$-xylene should have a highest $D$ value. This inference is evidenced by Figs. 4-6 and 8.

On the other hand, although $D$ values varied, $\Delta D$ values almost remained unchanged as the increase of solvent viscosity, indicating that solvent viscosity affects $D$ values but does not influence the resolution in these CNMR detections. The reason should be that the interaction between PVP and the components is stronger than that between solvent and the components, and the resolution ( $\Delta D$ values) is dominated by the stronger interaction.

The effect of the solvent polarity on resolution was observed through the experiments in different solvents. Figure 7 shows the ${ }^{1} \mathrm{H}$ DOSY spectra of $p$-xylene, benzyl alcohol, and $p$-methylphenol in $\mathrm{CD}_{3} \mathrm{OD}$ without and with PVP, respectively. As seen in Fig. 7(a), benzyl alcohol and $p$-methylphenol were not fully separated from each other, while $p$-xylene was resolved from the above two components in the absence of PVP; on the contrary, the three components were fully separated in the presence of PVP (Fig. 7(b)). The observation in $\mathrm{CD}_{3} \mathrm{OD}$ is different from that in $\mathrm{CDCl}_{3}$, where the three components had not been separated from each other in the absence of PVP. Therefore, solvent polarity not only influences the separation result of pure DOSY experiment but also changes the separation performance of CNMR.

\section{Influence of sample temperature on diffusion coefficient and resolution}

Temperature usually affects chromatographic separation, ${ }^{[34-36]}$ and similarly may impact CNMR measurements because molecular translational motion closely depends on sample temperature. In this work, the effect of experimental temperature on $D$ and $\Delta D$ values of three components was investigated. Figure 8 shows the

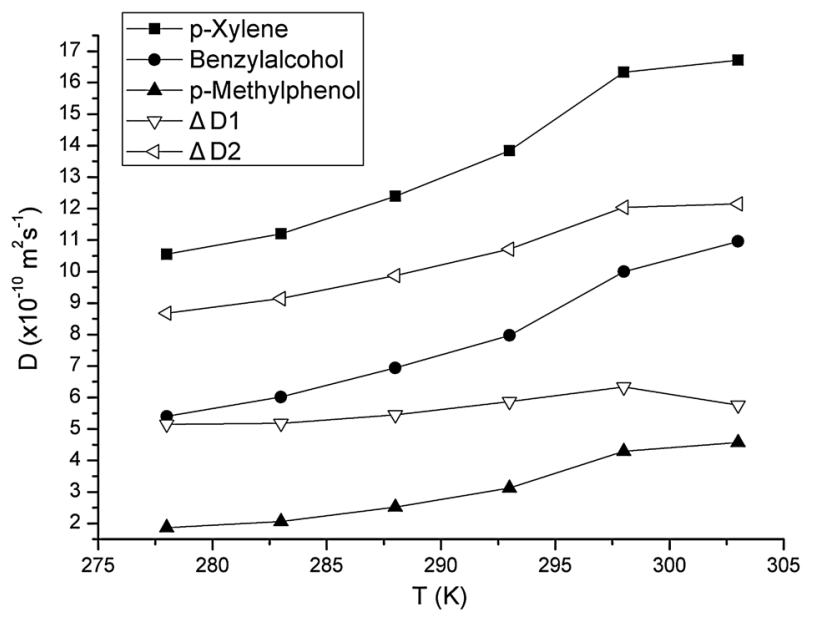

Figure 8. Influence of sample temperature $(T)$ on diffusion coefficient and resolution. PVP Mw: $10000 \mathrm{~g} / \mathrm{mol}$; PVP: $50 \mathrm{mg}$; each component: 20 mg; solvent: $0.6 \mathrm{ml} \mathrm{CDCl}$.

variation in $D$ values of three components along of the increase of temperature. The slope of the increase in $D$ value of the three components is in a sequence of $S_{p \text {-xylene }}>S_{\text {benzyl alcohol }}>S_{p \text { - }}$ methylphenol, which is reversed to the polarity sequence of $p$-xylene benzyl alcohol $<p$-methylphenol. This trend reveals that temperature more significantly affects the $D$ value of lower polar molecule and comparatively less affects that of higher polar molecule. With respect to the variation of $\Delta D, \Delta D_{1}$ increased slightly from 278 to $298 \mathrm{~K}$, then decreased above $298 \mathrm{~K}$. While $\Delta D_{2}$ almost increased as the temperature rose. The variation trend of $\Delta D_{1}$ and $\Delta D_{2}$ is different when the sample temperature is above $298 \mathrm{~K}$.

\section{Understanding the mechanism of resolution}

Stokes-Einstein equation shows that $T, \eta$, and $r_{s}$ are the three significant factors to affect $D$ value. The experimental results in the present work, however, reveal that molecular polarity significantly influences the $\Delta D$ values of three components in CNMR measurement. The different molecular polarity of the components causes the different strength of the interaction between the components and the VSP, leading to the change in $D$ and $\Delta D$ values. Therefore, the polarity of the components should principally impact the separation of the components. 


\section{Conclusions}

The effects of PVP concentration, PVP Mw, solvent viscosity, solvent polarity, and sample temperature on the $\Delta D$ values of $p$-xylene, benzyl alcohol, and $p$-methylphenol were investigated by the ${ }^{1} \mathrm{H}$ CNMR technique, and these 'chromatographic conditions' affected the $\Delta D$ values. As the increase of PVP concentration and PVP Mw, $\triangle D$ values increased. When the solvent consisted of $\mathrm{CDCl}_{3}$ and $\mathrm{CCl}_{4}$, the increased solvent viscosity did not change the $\Delta D$ values, while the separation result in $\mathrm{CDCl}_{3}$ was different from that in $C D_{3} O D$. In addition, $\Delta D_{2}$ increased along of the increase of temperature. While $\Delta D_{1}$ firstly slightly increased, and then decreased. $\Delta D_{1}$ was different from $\Delta D_{2}$ in the variation trend when the sample temperature is above $298 \mathrm{~K}$. Moreover, the molecular polarity of the components principally impacted the diffusion behavior and the separation for this 'normal-phase' CNMR.

\section{Acknowledgement}

The financial support from National Natural Science Foundation of China (21105108) is gratefully acknowledged.

\section{References}

[1] K. F. Morris, P. Stilbs, C. S. Johnson. Anal. Chem. 1994, 66, 211.

[2] C. Carrara, C. Lopez, S. Caldarelli. J. Chromatogr. A 2012, 1257, 204.

[3] C. Carrara, S. Caldarelli. J. Phys. Chem. C 2012, 116, 20030.

[4] R. Novoa-Carballal, E. Fernandez-Megia, C. Jimenez, R. Riguera. Nat. Prod. Rep. 2011, 28, 78.

[5] C. S. Johnson. Prog. Nucl. Magn. Reson. Spectrosc. 1999, 34, 203.

[6] S. Caldarelli. Magn. Reson. Chem. 2007, 45, S48.

[7] K. E. Price, L. H. Lucas, C. K. Larive. Anal. Bioanal. Chem. 2004, 378, 1405.

[8] J. S. Gounarides, A. D. Chen, M. J. Shapiro. J. Chromatogr. B 1999, 725, 79.

[9] J. S. Kavakka, I. Kilpelainen, S. Heikkinen. Org. Lett. 2009, 11, 1349.

[10] J. S. Kavakka, V. Parviainen, K. Wahala, I. Kilpelainen, S. Heikkinen. Magn. Reson. Chem. 2010, 48, 777.
[11] R. E. Joyce, I. J. Day. J. Magn. Reson. 2012, 220, 1.

[12] J. Cassani, M. Nilsson, G. A. Morris. J. Nat. Prod. 2012, 75, 131.

[13] C. F. Tormena, R. Evans, S. Haiber, M. Nilsson, G. A. Morris. Magn. Reson. Chem. 2010, 48, 550.

[14] M. E. Zielinski, K. F. Morris. Magn. Reson. Chem. 2009, 47, 53.

[15] C. Pemberton, R. E. Hoffman, A. Aserin, N. Garti. Langmuir 2011, 27, 4497.

[16] R. Evans, S. Haiber, M. Nilsson, G. A. Morris. Anal. Chem. 2009, 81, 4548.

[17] K. F. Morris, B. A. Becker, B. C. Valle, I. M. Warner, C. K. Larive. J. Phys. Chem. B 2006, 110, 17359.

[18] B. A. Begotka, J. L. Hunsader, C. Oparaeche, J. K. Vincent, K. F. Morris. Magn. Reson. Chem. 2006, 44, 586.

[19] S. R. Chaudhari, N. Suryaprakash. J. Mol. Struct. 2012, 1017, 106.

[20] C. Pemberton, R. Hoffman, A. Aserin, N. Garti. J. Magn. Reson. 2011, 208, 262.

[21] J. Xu, T. W. Tan, L. Kenne, C. Sandstrom. New J. Chem. 2009, 33, 1057.

[22] R. E. Hoffman, H. Arzuan, C. Pemberton, A. Aserin, N. Garti. J. Magn. Reson. 2008, 194, 295.

[23] C. Carrara, S. Viel, C. Delaurent, F. Ziarelli, G. Excoffier, S. Caldarelli. J. Magn. Reson. 2008, 194, 303.

[24] G. Pages, C. Delaurent, S. Caldarelli. Angew. Chem. Int. Ed. 2006, 45, 5950.

[25] S. Viel, F. Ziarelli, S. Caldarelli. Proc. Natl. Acad. Sci. U. S. A. 2003, 100, 9696.

[26] G. N. M. Reddy, R. Ballesteros-Garrido, J. Lacour, S. Caldarelli. Angew. Chem. Int. Ed. 2013, 52, 1.

[27] D. H. Wu, A. D. Chen, C. S. Johnson. J. Magn. Reson., Ser. A 1995, 115, 260.

[28] H. Y. Carr, E. M. Purcell. Phys. Rev. 1954, 94, 630.

[29] S. Meiboom, D. Gill. Rev. Sci. Instrum. 1958, 29, 688.

[30] F. Zhan, G. Yu, B. Yao, X. Guo, T. Liang, M. Yu, Q. Zheng, W. Weng. J. Chromatogr. A 2010, 1217, 4278.

[31] K. Le Mapihan, J. Vial, A. Jardy. Chromatographia 2003, 57, S163.

[32] U. D. Neue, C. H. Phoebe, K. Tran, Y. Cheng, Z. Lu. J. Chromatogr. A 2001, 925, 49.

[33] J. Barbosa, I. Toro, R. Berges, V. Sanz-Nebot. J. Chromatogr. A 2001, 915, 85.

[34] G. Paglia, O. D’Apolito, F. Tricarico, D. Garofalo, G. Corso. J. Sep. Sci. 2008, 31, 2424.

[35] Y. Yang. Anal. Chim. Acta 2006, 558, 7.

[36] D. Zhang, F. Li, D. H. Kim, H. J. Choi, M. H. Hyun. J. Chromatogr. A 2005, 1083, 89. 